\title{
Genç Futbolculara Uygulanan FIFA 11+ Eğitim Programının Performans Üzerine Etkisi*
}

\author{
The Effect of FIFA 11+ Training Program on the Performance \\ in Young Football Players
}

\author{
ORIJJINAL ARAŞTIRMA \\ ORIGINAL RESEARCH \\ Erdil DURUKAN ${ }^{1 \dagger}$, \\ Mehmet GÖKTEPE ${ }^{2}$, \\ Emrah AKÇA ${ }^{3}$
}

${ }^{1}$ Balıkesir Üniversitesi, BESYO, http://orcid.org/0000-0002-16271388

${ }^{2}$ Balıkesir Üniversitesi, BESYO, http://orcid.org/0000-0001-74470118

${ }^{3}$ Balıkesir Üniversitesi, Sağlık Bilimleri Enstitüsü, Beden Eğitimi ve Spor Anabilim Dalı http://orcid.org/0000-0001-91598260

\section{Yayın Bilgisi}

Gönderi Tarihi: 12.04 .2019

Kabul Tarihi: 18.06.2019

Online Yayın Tarihi: 30.06.2019

\begin{abstract}
$\ddot{O} z$
Uluslararası Futbol Federasyonları Birliği (FIFA)'nın ve Türkiye Futbol Federasyonu (TFF)'nin futbol takımlarına önerdiği FIFA 11+ adlı bir antrenman protokolü bulunmaktadır. $\mathrm{Bu}$ araştırmanın amacı, genç futbolculara uygulanan FIFA 11+ eğitim programının performans üzerine etkisini belirlemektir.Çalıșmaya, 2017-2018 futbol sezonu TFF Elit Akademi futbol Liginde bulunan, Demir Grup Sivasspor 14 yaş grubunda lisanslı olarak futbol oynayan toplam20 erkek futbolcu (Yaş 14, Vücut ağırlığı 51,93 $\pm 9,40$, boy uzunluğu $162,55 \pm 9,52)$ dahil edilmiştir. Çalışmaya katılmayı kabul eden her futbolcunun ailesinden de çalışma için izin alınmıştır. Sporculara 1. Gün sırasıyla: Boy ve kilo ölçümü, 10 dakika 1sınma koşusu ve Illinois çeviklik testi yaptırıldı. 2. Gün sırasıyla: 10 dakika ssınma koşusu ve 5,10 ve $30 \mathrm{~m}$ sürat testleri yapıldı. 3. Gün sırasıyla: 10 dakika 1sınma koşusu ve Yoyo dayanıklılık testi yaptırıldı. 4. Gün futbolculara rutin antrenman programlarına ek olarak 8 hafta sürecek şekilde haftada 3 gün FIFA 11+ eğitim programı uygulandı. 8 hafta sonunda yine 3 gün süren ölçümler aynen tekrar edildi ve çalışma sonlandırıldı. Bu araştırma Demir Grup Sivasspor tesislerinde yapıld1. İstatistiksel değerlendirme SPSS 22.0 program kullanılarak yapıldı. Ön test ve son testten elde edilen değerler, Shapiro-Wilk testi ile normallik dağılımına bakıldıktan sonra Wilcoxon İşaretli Sıralar testi yardımı ile istatistiksel olarak karşılaştırıldı. Elde edilen bulgulara göre; futbolculara uygulanan FIFA 11+ eğitim programının Yo-yo testi (KEM, MAKS, MaxVO 2, 2dkTOP), Sürat Testi $(5,10,30 \mathrm{~m})$ ve İllinois çeviklik testi değerlerine istatistiksel olarak olumlu düzeyde etkisinin olduğu tespit edilmiştir $(\mathrm{p}<0.01, \mathrm{p}<0,05)$. Sonuç olarak; futbolculara düzenli uygulanan FIFA $11+$ eğitim programının çeviklik, sürat ve dayanıklılık performansını geliştirebileceği, ayrıca toparlanmaya da olumlu yönde etki edeceği söylenebilir.
\end{abstract}

Anahtar kelimeler: Futbol, FİFA 11+ eğitim programı, performans.

\begin{abstract}
The "training protocol" FIFA 11+ includes the parameters, which have been proposed to football teams by FIFA and TFF. The purpose of this study is to determine the effect of FIFA $11+$ training program on the performance of young football players. The study was conducted with a total of 20 male football players (Age 14, weight 51,93 $\pm 9,40$, height 162,55 $\pm 9,52$ ) in 14-age group of Demir Grup Sivasspor Team that was in the TFF Elite Academy football league in 2017-2018 football seasons. Permissions from families were obtained for each player. The following procedures were conducted respectively on the first day of the study; weight and height measurements, 10-minute warm up run and Illinois agility test. On the second day; 10-minute warm up run, 5, 10 and 30-metres running speed tests were administered to the players. On the third day; 10-minute warm up run, Yo-Yo endurance test were conducted respectively and on the fourth day FIFA 11+ training program which was performed for 3 days per week for 8 weeks, was administered including the routine training program. After 8 weeks, 3-day measurements were repeated in the same way and then the study was finalized. This study was carried out in Demir Grup Sivasspor Facilities. SPSS 22.0 software was used for the statistical analyses. The values obtained from pre-test and post-test were compared statistically through Wilcoxon signed rank test after testing the normality by Shapiro-Wilk test. According to the findings; Coverage of FIFA 11+ training region Yo-yo test (KEM, MAKS, $\left.\mathrm{MaxVO}_{2}, 2 \mathrm{dkTOP}\right)$, Speed Test $(5,10,30 \mathrm{~m})$ and Illinois Agility Test has a significant value for football players $(\mathrm{p}<0.01, \mathrm{p}<0.05)$. As a result; footballers can regularly improve agility, speed and endurance in the FIFA $11+$ training zone, where it can be said to have a positive impact on recovery.
\end{abstract}

Keywords: Football, FIFA 11+, training program, performance.

\footnotetext{
*Bu çalışma 21-24 Mart 2019 tarihleri arasında Manisa/Türkiye'de yapılan II. Dünya Spor Bilimleri Araştırmaları Kongresi'nde Sözel Bildiri olarak sunulmuştur.
}

†Sorumlu Yazar: Erdil DURUKAN, erdurukan@hotmail.com 


\section{GİRIŞ}

Günümüz futbolu, daha karmaşık teknik becerilere, taktiksel düşüncedeki gelişmeye ve fiziki ihtiyaçlardaki artışa dayanmaktadır. Fiziki ihtiyaçlardaki, egzersizin şiddetindeki ve kat edilen toplam mesafedeki artış, en iyi takımların en iyi oyuncuları ile yaptıkları fazla sayıdaki müsabakaların bir sonucudur (Günay ve Yüce, 2008). Futbol oyunu, büyük bir alanda oynanması ve oyunculara verilen görevlerin çeşitlilik göstermesi nedeni ile bedensel ve fizyolojik özelliklere bağlı olduğunu göstermektedir. Futbol; kontrol gerektiren bir takım ve temas sporu olması nedeniyle üst düzey dayanıklılık kuvvet, sürat ve çabukluk gibi sportif performans istemektedir. Bu yüzden günümüzde kaleci dahil bütün mevkilerdeki oyuncuların her türlü motorik özelliklere sahip olmasını gerektirmektedir (Köklü, Özkan, Alemdaroğlu ve Ersöz 2009).

Sporcuların fiziksel performansları başarıları ile paralellik göstermektedir. $\mathrm{Bu}$ yüzden sporcuların fiziksel olarak performanslarını korumak ve artırmak için en az haftada iki kez düzenli olarak antrenman yapmaları gerekmektedir. $\mathrm{Bu}$ antrenman programları kuvvet, kardiyovasküler dayanıklılık, denge, çeviklik, dayanıklılık ve koşu gibi parametreleri içermelidir (Özkan ve ark., 2012). Bu parametreleri içeren ve Uluslararası Futbol Federasyonları Birliği (FIFA)'nin ve Türkiye Futbol Federasyonu (TFF)'nun futbol takımlarına önerdiği FIFA 11+ adlı bir antrenman protokolü bulunmaktadır. $\mathrm{Bu}$ protokolün amacı futbolcuların fiziksel performanslarını artırmak ve futbolcuları yaralanmalara karşı korumaktır (Bizzini ve ark., 2013). Birçok spor branşında olduğu gibi futbolcunun performansını oluşturan temel özellikler kuvvet, dayanıkl1lık, sürat ve vücut kompozisyonudur. Çeviklik ve reaksiyon ise futbolda çok önemli parametrelerdir. Çeviklik, bu belirli biyomotor özelliklerden oluşmakta ve bazılarından da önemli derecede etkilenmekte olan bir özellik olarak kendini göstermektedir (Brown ve Ferrigno, 2000).

Futbol, dikkat çekici bir yaralanma riski taşıyan yüksek yoğunluklu ve etkili bir takım sporudur. Futbolcularda yaş olarak yaralanma riski en yüksek oran 18 yaş altı sporculardadır. Özellikle ergenlik döneminde görülen hızlı büyüme kas-kemik yapıları arasındaki gelişim uyumsuzluğu, kas ve tendon yapılarının esnekliğinde yaralanma riskini artırır. Bu döneme özgü dikkatsiz ve atılgan davranışlar ile psikolojik özelliklere eklenen motor becerilerdeki sakarlık, koordinasyon ve denge yetilerinde geçici düşüş, yaralanma için uygun koşullan oluşturur (Koşar, Demirel, 
Aydoğ ve Doral, 2006). Literatüre baktığımızda FIFA 11+ eğitim programın genç oyuncuların performansına etkisinin incelendiği çalışmalar çok az sayıdadır. Bu nedenle araştırmamızın bulgularının literatüre katkı sağlaması açısından önemli olacağını düşünebilir. Yukarıdaki bilgiler ışığında araştırmamızın amacı genç futbolculara uygulanan FIFA 11+eğitim programının performans üzerine etkisini belirlemektir.

\section{GEREÇ VE YÖNTEM}

\section{Çalışma Grubu}

Çalı̧̧maya, 2017-2018 futbol sezonu TFF Elit Akademi futbol Liginde bulunan, Demir Grup Sivasspor 14 yaş grubunda lisanslı olarak futbol oynayan, fiziksel özellikleri (yaş 14, vücut ağırlığ $51,93 \pm 9,40$, boy uzunluğu 162,55 $\pm 9,52$ ) olan toplam 20 erkek futbolcu dâhil edilmiştir. Çalışmaya katılmayı kabul eden her futbolcunun ailesinden de çalışma için izin alınmıştır. Sporculara 1. Gün sırasıyla: Boy uzunluğu ve vücut ağırlığı ölçümü, 10 dakika ısınma koşusu ve Illinois çeviklik testi yaptırıldı. 2. Gün sırasıyla: 10 dakika 1sınma koşusu ve 5, 10 ve $30 \mathrm{~m}$ sürat testleri yapıldı. 3. Gün Sırasıyla: 10 dakika ısınma koşusu ve Yoyo dayanıklılık testi yaptırıldı. 4. Gün futbolculara rutin antrenman programlarına ek olarak 8 hafta sürecek şekilde haftada 3 gün FIFA 11+ eğitim programı uygulandı. 8 hafta sonunda yine 3 gün süren ölçümler aynen tekrar edildi ve çalışma sonlandırıldı. Bu araştırma Demir Grup Sivasspor tesislerinde yapıldı.

\section{Veri Toplama Aracı}

Boy uzunluğu ve Vücut Ağırlığı Öıçümleri: Deneklerin boy uzunlukları hassaslık derecesi $0.01 \mathrm{~m}$ olan (SECA, Almanya) boy ölçer ile vücut ağırlığı ölçümleri ise hassaslık derecesi $0.1 \mathrm{~kg}$ olan elektronik baskülle (SECA, Almanya) ölçülmüştür.

Vücut Kitle İndeksi (VKİ):VKİ, olguların vücut ağırlıklarının $\mathrm{kg}$ değerinin, boy uzunluğu metre ölçümünün karesine bölünmesi ile $\left(\mathrm{kg} / \mathrm{m}^{2}\right)$ hesaplanmıştır (Moran ve McGlynn, 1997; Norris ve ark., 2005; Taylor, Keil, Gold, Williams ve Goulding, 1998).

Kalp Atım Sayısının Belirlenmesi: Futbolcuların kalp atım sayıları Polar Team 2 nabız ölçer ile belirlendi.

\section{Yo-Yo Dayanıklıık Testi:}

Test 20 m'lik koşu alanı ve 5 m'lik aktif toparlanma alanı olmak üzere iki kısımdan oluşmaktadır (şekil 1). Denekler önce 20 m'lik bölümü git-gel şeklinde olmak kaydıyla tamamladıktan sonra 5 
m'lik aktif toparlanma bölümünü yine git-gel şeklinde jogging yaparak tamamlamışlardır. Aktif toparlanma süresi 10 saniye olarak belirlenmiştir. Test $10 \mathrm{~km} / \mathrm{h}$ hızla başlayıp test protokolünün ön gördüğü şekilde artmıştır. Deneklerin, yo-yo test düzeneğinin lisanslı cd'sinden bilgisayar aracılığıyla gelen ses yardımı ile tempolarını ayarlamaları sağlanmıştır. Test, kişi tükenme noktasına geldiğinde ve/veya ardı ardına üç sesi kaçırması durumunda sonlandırılmıştır. $\mathrm{VO}_{2}$ maks değeri aşağıdaki formül kullanılarak hesaplanmıştır.

Eşitlik 3.2: $\mathrm{Y}=24.8+(0.014 * \mathrm{X})($ Bangsbo, 1996)

$\left(\mathrm{Y}=\mathrm{VO}_{2}\right.$ maks ml kg-1 dak-1, $\mathrm{X}=$ koşu mesafesi $)$

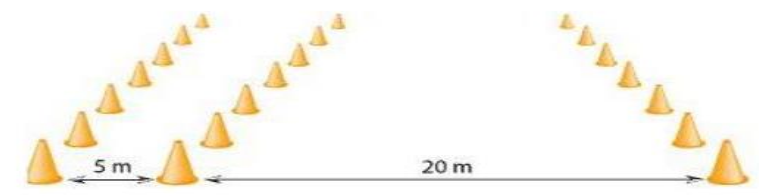

Şekil 1. Yo-yo testi

\section{Illinois Çeviklik Testi (IÇT):}

Katılımcıların çeviklik yeteneğini belirlemek için her 10 metrede $180^{\circ}$ dönüşleri içeren ve 40 metre düz koşu, 20 metre huniler arasındaki slalom koşusundan meydana gelen Illinois çeviklik testi (şekil 2) uygulandı. Futbolcular çeviklik testine, yüzüstü yatar pozisyonda ve eller omuz hizalarında yerle temasta iken başlar ve minimal sürede bitirmeye çalışırlar. Katılımcıların test alanına alışabilmesi için deneme yapmalarına izin verilir. En iyi koşu derecesini sağlamak için test katılımcılara 2 kez (3-4 dakika dinlenme ile) uygulanır ve en iyi koşu zamanı saniye (sn) cinsinden fotosel cihazı yardımıyla kaydedildi (Başkaya, Ünveren ve Karavelioğlu, 2018; Can, Özmen ve Bayrakdaroğlu, 2017).

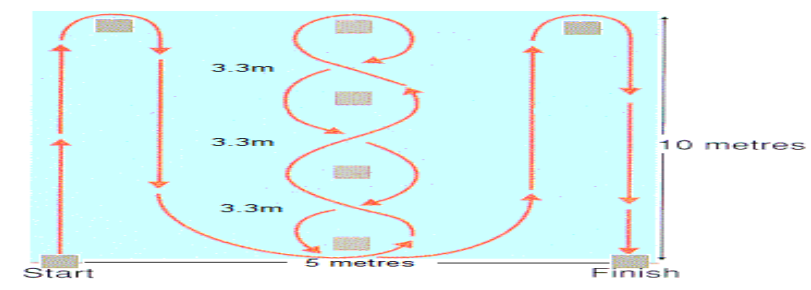

Şekil 2. İllinois çeviklik testi

\section{5,10 ve 30 Metre Sürat Performanslarının Belirlenmesi:}

5-10-30 metre Sürat testleri kauçuk zeminli kapalı bir alanda gerçekleştirilmiştir. Testler ikişer defa tekrarlanmış ve en iyi skor test skoru olarak kabul edilmiştir. Sürat testleri arasında 3'er 
Durukan, E., Göktepe, M., ve Akça, E. (2019). Genç Futbolculara Uygulanan FIFA 11+ Eğitim Programının Performans Üzerine Etkisi. CBÜ Beden Eğitimi ve Spor Bilimleri Dergisi, 14(1),129-138.

dakika dinlenme verilmiştir. Katılımcıların sürat süreleri (BrowerTimingSystems, Draper, UT) kablosuz fotosel kullanılarak kaydedilmiştir (Dinç ve Hayta, 2018).

\section{Araştırmada Uygulanan FIFA 11+ Eğitim Programı:}

Çalışmadaki eğitim grubuna FIFA 11+ eğitim programı uygulandı. Bu eğitim programı FIFA' nın oluşturduğu uzman bir grup tarafından Oslo Spor Yaralanmaları Araştırma Merkezi, Santa Monica Ortopedi ve Sporcu Sağlığı Araştırma Vakfı ve FIFA Tıbbi Değerlendirme ve Araştırma Merkezi sponsorluğunda geliştirilmiştir. FIFA 11+ eğitim programı; basit, kolayca hatırlanabilir ve az zaman alan, spora özel olan, fairplay’i öne çıkaran egzersizlerden oluşmaktadır. FIFA 11+eğitim programı 3 bölüme ayrılır. İlk bölüm koşu egzersizleri, ikinci bölüm kuvvet, denge, kas kontrol ve gövde stabilizasyonunu geliştiren 6 egzersiz, üçüncü bölüm ilerlemiş koşu egzersizlerinden oluşmaktadır. FIFA 11+ eğitim programı yaklaşık 20-25 dk sürmektedir ve bilinen genel germe egzersizlerinden önce yapılmaktadır. Egzersizler gövde stabilizasyonu, nöromusküler kontrol ve egzentrik hamstring kasları kuvvetlendirme ve çeviklik üzerine yoğunlaşmaktadır (Tablo 1). Bu egzersizler haftada üç defa yapılmalıdır (Daneshjoo ve ark., 2012a; K1z1lc1, 2014).

Tablo 1. FIFA 11+eğitim programı egzersiz süreleri ve setleri

\begin{tabular}{|c|c|c|c|c|c|c|c|c|c|}
\hline \multirow{2}{*}{$\begin{array}{l}\text { EGZERSİLER } \\
\text { BÖLÜM 1: KOŞU EGZERSİLERİ }\end{array}$} & \multicolumn{3}{|c|}{ 1-3.Hafta } & \multicolumn{3}{|c|}{ 4-5.Hafta } & \multicolumn{3}{|c|}{ 6-8.Hafta } \\
\hline & Set & Tekrar & Süre & Set & Tekrar & Süre & Set & Tekrar & Süre \\
\hline $\begin{array}{l}\text { Düz koşu, Kalça dışa, Kalça içe, Eş değişimli, Omuz } \\
\text { omuza, İleri-geri }\end{array}$ & 2 & 1 & $8 \mathrm{dk}$ & 2 & 1 & $8 \mathrm{dk}$ & 2 & 1 & $8 \mathrm{dk}$ \\
\hline \multicolumn{10}{|l|}{$\begin{array}{l}\text { BÖLÜM } 2 \text { : KUVVET, PLİOMETRİK VE DENGE } \\
\text { EGZERSİLERİ }\end{array}$} \\
\hline $\begin{array}{l}\text { Yüzüstü Bench: Statik, Bacaklar değişerek, Tek ayak } \\
\text { üstünde }\end{array}$ & 3 & 1 & $\begin{array}{c}20-30 \\
\text { sn }\end{array}$ & 3 & 1 & $\begin{array}{l}40- \\
60 \\
\text { sn }\end{array}$ & 3 & 1 & $\begin{array}{l}40- \\
60 \mathrm{sn}\end{array}$ \\
\hline Yan Yatış: Kol ve ayak üzerinde düzgün duruş & 3 & 1 & $\begin{array}{l}20-30 \\
\text { sn }\end{array}$ & 3 & 1 & $\begin{array}{l}20- \\
30 \\
\mathrm{sn}\end{array}$ & 3 & 1 & $\begin{array}{c}20- \\
30 \mathrm{sn}\end{array}$ \\
\hline $\begin{array}{l}\text { Hamstring: Başlangıç (3-5), orta seviye(7-10 )ileri } \\
\text { seviye(12-15 ) }\end{array}$ & 1 & $3-5$ & $60 \mathrm{sn}$ & 1 & $7-10$ & $\begin{array}{l}60 \\
\mathrm{sn}\end{array}$ & 1 & $12-15$ & $60 \mathrm{sn}$ \\
\hline $\begin{array}{l}\text { Tek ayak üzerinde denge: (1-3. Hafta) Sabit top } \\
\text { tutma,(4-5. Hafta) Karş1lıklı top atma, (6-8. Hafta) Eşini } \\
\text { iterek }\end{array}$ & 2 & 1 & $30 \mathrm{sn}$ & 2 & 1 & $\begin{array}{l}30 \\
\text { sn }\end{array}$ & 2 & 1 & $30 \mathrm{sn}$ \\
\hline $\begin{array}{l}\text { Çömelme: (1-3. Hafta) Parmak ucunda, (4-5. Hafta) Öne } \\
\text { doğru, (6-8. Hafta) Tek ayak üzerinde eşli }\end{array}$ & 2 & 1 & $30 \mathrm{sn}$ & 2 & $\begin{array}{c}10 \\
\text { Her } \\
\text { bacak }\end{array}$ & $\begin{array}{l}30 \\
\text { sn }\end{array}$ & 2 & $\begin{array}{c}10 \\
\text { Her } \\
\text { bacak }\end{array}$ & $30 \mathrm{sn}$ \\
\hline $\begin{array}{l}\text { Zıplama: (1-3. Hafta) Olduğu yerde, (4-5. Hafta) Yana } \\
\text { zıplama, (6-8. Hafta) Dört yönlü zıplama }\end{array}$ & 2 & 1 & $30 \mathrm{sn}$ & 2 & 1 & $\begin{array}{l}30 \\
\text { sn }\end{array}$ & 2 & 1 & $30 \mathrm{sn}$ \\
\hline \multicolumn{10}{|l|}{ BÖLÜM 3: İLERLEMİŞ KOŞU EGZERSİZLERİ } \\
\hline Tempolu koşu, Büyük adımlarla, ZigZag koşu & 2 & 1 & $2 \mathrm{dk}$ & 2 & 1 & $2 \mathrm{dk}$ & 2 & 1 & $2 \mathrm{dk}$ \\
\hline Toplam & & & 20 & & & 22,5 & & & 25 \\
\hline
\end{tabular}




\section{Verilerin Analizi:}

İstatistiksel değerlendirme SPSS 22.0 (SPSS Inc., Chicago, IL, USA) programı kullanılarak yapıld1. Ön test ve son testten elde edilen değerler, Shapiro-Wilk testi ile normallik dağılımına bakıldıktan sonra Wilcoxon İşaretli Sıralar testi yardımı ile istatistiksel olarak karşılaştırıldı. Bütün sonuçlar \%95 güven aralığında değerlendirilip, $\mathrm{p}<0.05$ değeri anlamlı kabul edilmiştir. Anlamlılık düzeyinin daha yüksek olduğu $(\mathrm{p}<0.01)$ bulgular da elde edilmiştir.

\section{BULGULAR}

Tablo 2. Çalışmaya katılan futbolcuların fiziksel özellikleri

\begin{tabular}{cccccc}
\hline $\mathbf{N}$ & Yaş (yıl) & Boy Uzunluğu (cm) & Vücut Ă̆ırlı̆̆ı (kg) & VKİ(kg/m $\mathbf{m}^{\mathbf{2}}$ & Spor Yaşı (yıl) \\
\hline 20 & 14 & $162,55 \pm 9,52$ & $51,93 \pm 9,40$ & $19,50 \pm 1,90$ & $5,95 \pm 0,94$ \\
\hline
\end{tabular}

Tablo 2'de katılımcıların yaş, boy, vücut ağrılığı, VKİ ve spor yaşları değerleri verilmiştir.

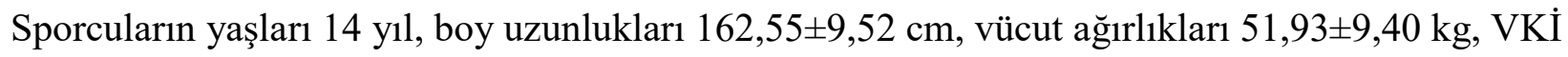
$19,50 \pm 1,90\left(\mathrm{~kg} / \mathrm{m}^{2}\right)$ ve spor yaşları 5,95 $\pm 0,94$ yıl olarak tespit edilmiştir.

Tablo 3: Çalışmaya katılan futbolcuların yo-yo testi, illinois çeviklik testi ve sürat testi skorları tanımlayıcı istatistiği

\begin{tabular}{|c|c|c|c|c|c|c|c|c|c|}
\hline & \multirow{2}{*}{ PARAMETRELER } & \multicolumn{4}{|c|}{ Ön test (N:20) } & \multicolumn{4}{|c|}{ Son test (N:20) } \\
\hline & & Min. & Maks. & Ort. & SS & Min. & Maks. & Ort. & SS \\
\hline \multirow{4}{*}{$\begin{array}{l}\text { YO-YO } \\
\text { TESTII }\end{array}$} & $\begin{array}{l}\text { Kat edilen mesafe }(\mathbf{m}) \\
\text { (KEM) }\end{array}$ & 840,00 & 2320,00 & 1780,00 & 341,76 & 1440,00 & 2520,00 & 2111,00 & 244,22 \\
\hline & $\begin{array}{l}\text { Maksimal kalp atım sayısı } \\
\text { (MAKS) }\end{array}$ & 172,00 & 211,00 & 196,40 & 12,26 & 189,00 & 212,00 & 201,20 & 8,35 \\
\hline & $\begin{array}{l}2 \text { dk sonra toparlama kalp atım } \\
\text { sayısı (2dkTOP) }\end{array}$ & 129,00 & 173,00 & 148,05 & 13,25 & 126,00 & 158,00 & 137,45 & 7,53 \\
\hline & $\operatorname{MaxVO}_{2}(\mathrm{ml} / \mathrm{kg} / \mathrm{dak})$ & 43,46 & 55,89 & 51,35 & 2,87 & 48,50 & 57,57 & 54,13 & 2,05 \\
\hline $\begin{array}{c}\text { ILLİNOİS } \\
\text { ÇEVİKLİK } \\
\text { TESTİ }\end{array}$ & (sn) & 16,57 & 18,50 & 17,37 & 0,56 & 15,01 & 18,48 & 16,75 & 0,94 \\
\hline \multirow{3}{*}{$\begin{array}{c}\text { SÜRAT } \\
\text { TESTİ }\end{array}$} & 5mt (sn) & 1,04 & 1,27 & 1,17 & 0,06 & 1,02 & 1,26 & 1,15 & 0,06 \\
\hline & 10mt (sn) & 1,84 & 2,19 & 1,99 & 0,10 & 1,66 & 2,21 & 1,95 & 0,14 \\
\hline & 30mt (sn) & 4,42 & 5,26 & 4,82 & 0,25 & 4,20 & 5,20 & 4,73 & 0,31 \\
\hline
\end{tabular}

Tablo 3'de çalışmaya katılan futbolcuların yo-yo testi, illinois çeviklik testi ve sürat testi ortalama değerleri verilmiştir. 
Tablo 4. Çalışmaya katılan futbolcuların ön test ve son test yo-yo dayanıklılık, sürat ve çeviklik performansları arasındaki farkın anlamlılığını test etmek için yapılan wilcoxon işaretli sıra testi sonuçları

\begin{tabular}{|c|c|c|c|c|c|c|}
\hline & Son Test - Ön Test & $\mathbf{N}$ & $\begin{array}{c}\text { Sira } \\
\text { Ortalaması }\end{array}$ & $\begin{array}{c}\text { Sira } \\
\text { Toplamı }\end{array}$ & $\mathbf{z}$ & $\mathbf{p}$ \\
\hline \multirow{12}{*}{ YO-YO TESTI } & \multirow{3}{*}{$\begin{array}{l}\text { Kat edilen mesafe (m) } \\
\text { (KEM) }\end{array}$} & 1(a) & 14,50 & 14,50 & \multirow{3}{*}{$-3,391(b)$} & \multirow{3}{*}{$0,001 * *$} \\
\hline & & 19(b) & 10,29 & 195,50 & & \\
\hline & & $0(\mathrm{c})$ & & & & \\
\hline & \multirow{3}{*}{$\begin{array}{l}\text { Maksimal kalp atım sayısı } \\
\text { (MKAS) }\end{array}$} & 3(a) & 6,00 & 18,00 & \multirow{3}{*}{$-2,963(b)$} & \multirow{3}{*}{$\mathbf{0 , 0 0 3 * *}$} \\
\hline & & $15(\mathrm{~b})$ & 10,20 & 153,00 & & \\
\hline & & $2(\mathrm{c})$ & & & & \\
\hline & \multirow{3}{*}{$\begin{array}{l}2 \text { dk sonra toparlama kalp } \\
\text { atım sayısı (2dkTOP) }\end{array}$} & $16(\mathrm{a})$ & 10,06 & 161,00 & \multirow{3}{*}{$-3,294(a)$} & \multirow{3}{*}{$\mathbf{0 , 0 0 1} * *$} \\
\hline & & 2(b) & 5,00 & 10,00 & & \\
\hline & & $2(\mathrm{c})$ & & & & \\
\hline & \multirow{3}{*}{$\operatorname{MaxVO}_{2}(\mathrm{ml} / \mathrm{kg} / \mathrm{dak})$} & $1(\mathrm{a})$ & 14,50 & 14,50 & \multirow{3}{*}{$-3,391(a)$} & \multirow{3}{*}{$\mathbf{0 , 0 0 1} * *$} \\
\hline & & $19(\mathrm{~b})$ & 10,29 & 195,50 & & \\
\hline & & $0(\mathrm{c})$ & & & & \\
\hline \multirow{9}{*}{ SÜRAT TESTİ } & \multirow{3}{*}{5 metre (sn) } & 12(a) & 8,96 & 107,50 & \multirow{3}{*}{$-2,723(a)$} & \multirow{3}{*}{$0,006 * *$} \\
\hline & & $3(b)$ & 4,17 & 12,50 & & \\
\hline & & $5(\mathrm{c})$ & & & & \\
\hline & \multirow{3}{*}{10 metre (sn) } & $15(\mathrm{a})$ & 10,90 & 163,50 & \multirow{3}{*}{$-2,193(a)$} & \multirow{3}{*}{$\mathbf{0 , 0 2 8 *}$} \\
\hline & & $5(\mathrm{~b})$ & 9,30 & 46,50 & & \\
\hline & & $0(\mathrm{c})$ & & & & \\
\hline & \multirow{3}{*}{30 metre (sn) } & $16(\mathrm{a})$ & 10,72 & 171,50 & \multirow{3}{*}{$-3,082(a)$} & \multirow{3}{*}{$0,002 * *$} \\
\hline & & $3(\mathrm{~b})$ & 6,17 & 18,50 & & \\
\hline & & $1(\mathrm{c})$ & & & & \\
\hline \multirow{3}{*}{\multicolumn{2}{|c|}{ Illinois Çeviklik Testi (sn) }} & $18(\mathrm{a})$ & 11,22 & 202,00 & \multirow{3}{*}{$-3,622(a)$} & \multirow{3}{*}{$\mathbf{0 , 0 0 0} * *$} \\
\hline & & $2(b)$ & 4,00 & 8,00 & & \\
\hline & & $0(\mathrm{c})$ & & & & \\
\hline
\end{tabular}

*p $<0.05),{ }^{* *}(\mathbf{p}<0.01){ }^{(\mathrm{a})}$ Son Test $<$ Ön Test, ${ }^{(\mathrm{b})}$ Son Test $>$ Ön test $){ }^{(\mathrm{c})}$ Son Test $\left.=\ddot{O ̈ n ~ T e s t ~}\right)$

Tablo 4'e bakıldığında; Çalışmaya katılan futbolculara uygulanan FIFA 11+ eğitim programının Yo-yo testi (KEM, MAKS, MaxVO 2 , 2dkTOP), Sürat Testi $(5,10,30 \mathrm{~m})$ ve Illinois çeviklik testi değerleri ile istatistiksel olarak olumlu düzeyde etkisinin olduğu tespit edilmiştir $(\mathrm{p}<0.01, \mathrm{p}<0,05)$. Bu konuda futbolculara uygulanan FIFA 11+ eğitim programı sonras1, kat edilen mesafe, MaksVO2, toparlanma, sürat performansı ve Çeviklik performansı değerleri lehine anlamlı bir farklılık bulunmuştur.

\section{TARTIŞMA}

Sporda hedeflenen başarıya ulaşabilmek için, fiziksel ve fizyolojik uygunluğun yapılan spor branşının özelliklerine göre istenilen seviyede olması gerekmektedir. Aksi bir durumda hedeflenen sportif performansa tam olarak ulaşılamaz. Performans boy, vücut ağırlığı, BKİ gibi fiziksel yapının dışında motorik özelliklerden de (aerobik ve anaerobik dayanıklılık, kuvvet, sürat ve esneklik) etkilenir (Kalyon, 1990). Futbolda performans teknik, biyomekanik, taktik, mental ve fizyolojik alanlar gibi birçok değişkene bağlı olarak gelişir (Reilly ve Williams, 2005). 
Çalışmamızın bulgularına göre; futbolculara uygulanan FIFA 11+ eğitim programının Yo-yo testi (KEM, MAKS, $\left.\mathrm{MaxVO}_{2}, 2 \mathrm{dkTOP}\right)$, Sürat Testi $(5,10,30 \mathrm{~m})$ ve Illlinois çeviklik testi değerlerine istatistiksel olarak olumlu düzeyde etkisinin olduğu tespit edilmiştir $(\mathrm{p}<0.01, \mathrm{p}<0,05)$.

Core stabilizasyonu, uyluk kaslarının eksantrik antremanı, propriyoseptif antreman, dinamik stabilizasyon ve postüral uyumu iyi duruma getirmek için yapılan plyometrik antrenmanlar üzerine odaklanan egzersizleri içeren FIFA11+ programının (Barengo ve ark., 2014) literatürde; amatör futbolcularda uyluk kası kuvveti, sıçrama yüksekliği, sprint sürati ve bir takım denge ve propriyosepsiyon özelliklerinde önemli gelişmelere yol açacağı ifade edilmiştir (Daneshjoo ve ark., 2012a; Bizzini ve ark., 2013; Impellizzeri ve ark., 2013; Brito ve ark., 2010; Steffen ve ark., 2013; Nakase ve ark., 2013; Daneshjoo ve ark. 2012b) . Bahsedilen söz konusu araştırmalarda, FIFA 11+eğitim programının performansı arttırdığı sonucuna varılmıştır (Reis, Rebelo, Krustrup ve Brito, 2013; Steffen ve ark., 2013). Bizzini ve ark., (2013) yapmış oldukları çalışmada, FIFA 11+ programında yer alan egzersizlerin; yaralanma riskini azaltmak için etkili olmasının yanı sıra, performansı artırabilecek pozitif akut fizyolojik tepkileri tetiklemek için de yeterli olduğunu belirtmiş olup ayrıca sprint hızı, çeviklik, sıçrama performansı ve denge dahil olmak üzere bir dizi performans değişkeninde FIFA11+ programı sonrası istatistiksel olarak gelişmelerin olduğunu ifade etmişlerdir. Impellizzeri ve ark. (2013) 6 futbol takımının katıldığı bir çalışmada 42 birey deney grubu 39 birey kontrol grubu olmak üzere 81 amatör futbolcu üzerinde geleneksel ısınma programı ile FIFA 11+ eğitim programının performans üzerine etkisini araştırmıştır. FIFA 11+ programın 9 hafta boyunca hafta da 3 gün uygulamıştır. İlk 3 hafta seviye 1, ikinci 3 hafta seviye 2, son 3 hafta ise seviye 3 kuvvetlendirme egzersizleri uygulanmıştır. Sonuçlara bakıldığında core stabilizasyonun olumlu yönde etkilendiği görülmüştür. Yapılan bir diğer çalışmada ise FIFA 11+ eğitim programının, Portekizli erkek futsal oyuncuların performansını artırdığı tespit edilmiştir (Brito, Figuerido ve Fernandes, 2010). Daneshjoo ve ark., (2012a) yapmış olduğu çalışmada, FIFA 11+programının 2 ay boyunca antrenmanın 1sınma bölümünde uyguladıkları Asyalı erkek oyuncuların diz kuvveti oranlarında artışın yanı sıra, statik / dinamik denge ve çeviklik becerilerinde olumlu düzeyde artışa neden olduğunu tespit etmişlerdir. Yukarıdaki araştırmaların bulguları çalışmamızın bulgularını desteklemektedir. Başka bir çalışmada ise; Talović ve ark., (2017) çalışmalarının sonucunda FIFA 11+ programının uygulanmasının, belirli fiziksel parametrelerin (denge, hız, kuvvet, kas içi koordinasyon) ve 
Durukan, E., Göktepe, M., ve Akça, E. (2019). Genç Futbolculara Uygulanan FIFA 11+ Eğitim Programının Performans Üzerine Etkisi. CBÜ Beden Eğitimi ve Spor Bilimleri Dergisi, 14(1),129-138.

oyuncuların teknik becerilerinin (top sürme) gelişimini etkileyebileceğini belirtmişlerdir. $\mathrm{Bu}$ çalışmanın sonucu çalışmamızın sonucu ile benzerlik göstermektedir. Gatterer, Ruedl, Faulhaber, Regele ve Burtscher, (2012) yapmış oldukları çalışmanın sonucunda FIFA 11+ programının orta seviyedeki futbolcuların performansına etki etmediğini tespit etmişlerdir. Bu çalışmanın sonucu ile çalışmamızın sonucu paralellik göstermemektedir.

\section{SONUÇ}

Sonuç olarak; futbolculara düzenli uygulanan FIFA 11+ eğitim programının çeviklik, sürat, dayanıklılık performansını geliştirebileceği, ayrıca toparlanmaya da olumlu etki edeceği söylenebilir. Bu sonuçlar doğrultusunda futbolculara uygulanacak FIFA 11+ eğitim programının dayanıklılık, sürat ve çeviklik performanslarına katkı sağlaması açısından antrenman programlarında göz önünde bulundurulmasını önerebiliriz.

\section{KAYNAKLAR}

Bangsbo, J. (1996). YO-YO Tests. HO + Strom, Copenhagen, Denmark.

Barengo, N.C., Meneses-Echávez, J.F., Ramírez-Vélez, R., Cohen, D.D., Tovar, G., ve Bautista, J.E.C. (2014). The Impact of the FIFA 11+ Training program on injury prevention in football players: A Systematic Review. International Journal of Environmental Research and Public Health, 11, 11986-12000.

Başkaya, G., Ünveren, A., \& Karavelioğlu, M.B. (2018). Comparison of some physiological and motoric characteristics of female soccer and futsal players. Journal of Physical Education \& Sports Science/Beden Egitimi ve Spor Bilimleri Dergisi, 12(1), 12-20.

Bizzini, M., Impellizzeri, F.M., Dvorak, J., Bortolan, L., Schena, F., Modena, R., et al. (2013). Physiological and performance responses to the "FIFA 11+" (part 1): is it an appropriate warm-up?, Journal of Sports Sciences,31(13), 1481-1490.

Brito, J., Figuerido, P., \& Fernandes, L. (2010). Isokinetic Strength Effects of FIFA's "The 11+" Injury Prevention Training Programme, Isokinetics and Exercise Science, 18(4), 211-215.

Brown, L.E., Ferrigno, V.A., (2000). Training for Speed, Agility and Quickness, Human Kinetics, Champaign, IL.

Can, İ., Özmen, M., \& Bayrakdaroğlu, S. (2017). Antrenmanlı sporcularda çeviklik ve ağırlıklı squat sıçrama egzersizi esnasındaki hız ve güç değerleri arasındaki ilişki. CBÜ Beden Ĕ̆itimi ve Spor Bilimleri Dergisi, 12(2), 136-144.

Daneshjoo, A., Mokhtar, A.H., Rahnama, N. ve Yusof, A. (2012a). The Effects of injury prevention warm-up programmes on knee strength in male soccer players. PLoS One,7(12), e50979.

Daneshjoo, A., Mokhtar A.H., Rahnama, N. ve Yusof A. (2012b). The effects of comprehensive warm-up programs on proprioception, static and dynamic balance on male soccer players. PLoS One,7(12), e51568.

Dinç, N., \& Hayta, Ü, (2018). Sirkadiyen ritmin anaerobik güç üzerine etkisinin incelenmesi. Gaziantep Üniversitesi Spor Bilimleri Dergisi, 3(4), 77-86. 
Durukan, E., Göktepe, M., ve Akça, E. (2019). Genç Futbolculara Uygulanan FIFA 11+ Eğitim Programının Performans Üzerine Etkisi. CBÜ Beden Ĕ̈itimi ve Spor Bilimleri Dergisi, 14(1),129-138.

Gatterer, H., Ruedl, G., Faulhaber, M., Regele, M., \& Burtscher, M. (2012). Effects of the performance level and the FIFA "11" injury prevention program on the 1njury rate in 1talian male amateur soccer players. The Journal of Sports Medicine and Physical Fitness, 52(1), 80-84.

Günay, M. \& Yüce, A. (2008). Futbol Antrenmanının Bilimsel Temelleri. Ankara: Gazi Kitabevi.

Impellizzeri, F.M., Bizzini, M., Dvorak, J., Pellegrini, B., Schena, F., \& Junge, A. (2013). Physiological and performanc eresponses to the FIFA 11+ (part 2): A randomised controlled trial on the training effects. Journal of Sports Sciences, 31(13), 1491-1502.

Kalyon, T.A. (1990). Spor hekimliği, sporcu sağlı̆̆ı ve spor sakatlıklarl. Ankara: GATA Basımevi.

Kızılcı, M.H. (2014). Ampute futbolcularda FIFA 11+ programının fiziksel uygunluk düzeyine Etkisi. Yayımlanmamış Doktora Tezi, Hacettepe Üniversitesi, Ankara.

Koşar, N.Ş., Demirel, H.A., Aydoğ, T.S., \& Doral, M.N. (2006). Adolesanlarda sporcu sağlı̆̆ı. Türkiye Klinikleri Journal of Pediatric Science, 2(7), 25-33.

Köklü, Y., Özkan, A., Alemdaroğlu, U. \& Ersöz, G. (2009). Genç futbolcuların bazı fiziksel uygunluk ve somatotip özelliklerinin oynadıkları mevkilere göre karşılaştırılması. Spormetre Beden Eğitimi ve Spor Bilimleri Dergisi, VII (2), 61-68.

Moran, G.T. \& Mcglynn, G. (1997). Dynamics of training and conditioning. Second Edition. USA: WBC/Mcgraw-Hill.

Nakase, J., Inaki, A., Mochizuki, T., Toratani, T., Kosaka, M., Ohashi, Y., et al. (2013). Whole body muscle activity during the FIFA 11+ program evaluated by positron emission tomography. PLoS ONE, 8(9), e73898.

Norris, J.M., Langefeld, C.D., Scherzinger A.L., Rich, S.S., Bookman, E., Beck S.R., et al. (2005). Quantitative Trait Loci For Abdominal Fat and BMI in Hispanic-Americans and African-Americans: The IRAS Family Study, International Journal of Obesity, 29(1), 67-77.

Özkan, A., Kayıhan, G., Köklü, Y., Ergun, N., Koz, M., Ersöz G., et al. (2012). The Relationship Between Body Composition, Anaerobic Performance and Sprint Ability of Amputee Soccer Players, Journal of Human Kinetics, 35, 141-146.

Reilly, T. \& Williams, A.M. (2005). Science and soccer (second edition). London: Routledge-Taylor \& Francis Group.

Reis, I., Rebelo, A., Krustrup, P., \& Brito, J. (2013). Performance enhancement effects of federation internationale de football association's "The 11+" injury prevention training program in youth futsal players. Clinical Journal of Sport Medicine, 23(4), 318-320.

Steffen, K., Emery, C.A., Romiti, M., Kang, J., Bizzini, M., Dvorak, J., et al. (2013). High adherence to a neuromuscular injury prevention programme (FIFA 11+) improves functional balance and reduces injury risk in Canadian youth female football players: a cluster randomised trial. British Journal of Sports Medicine, 47(12), 794-802.

Talović, M., Alić, H., Ormanović, Š., Jelešković, E., Mustafović, M., \& Čaušević, D. (2017). Training Effects of FIFA 11+ Programme: A Brief Literature Review. Acta Kinesiologica International Scientific Journal of Kinesiology, 11(Supp. 2), 51-57.

Taylor, R.W., Keil, D., Gold, E.J., Williams, S.M., \& Goulding, A. (1998), Body Mass Index, Waist Girth and Waist-to-Hip Ratio as Indexes of Total and Regional Adiposity in Woman: Evalution Using Receiver Operating Characteristics Curves. The American Journal of Clinical Nutrition, 67(1), 44-49. 